Esta obra está bajo una Licencia Creative Commons Atribución - No Comercial - Sin Derivar 4.0 Internaciona

(c) $(\mathbb{Q} \Theta \Theta$

Construcción audiovisual de las prácticas culturales en torno a las celebraciones de los quince años en Cuba Maribel Acosta Damas, Zenaida Costales Pérez, Beatriz Rosales Vicente

Question, Vol. 1, N.62, e155, abril-junio 2019

ISSN 1669-6581 | https://doi.org/10.24215/16696581e155

http://perio.unlp.edu.ar/ojs/index.php/question

FPyCS | Universidad Nacional de La Plata

La Plata | Buenos Aires | Argentina

\title{
Construcción audiovisual de las prácticas culturales en torno a las celebraciones de los quince años en Cuba
}

\author{
Audiovisual construction of cultural practices associated \\ with the celebration of fifteen years old in Cuba
}

\author{
Maribel Acosta Damas acostamad@yahoo.es \\ https://orcid.org/0000-0002-1209-2868 \\ Zenaida Costales Pérez postgrado@fcom.uh.cu \\ https://orcid.org/0000-0001-9561-5144 \\ Beatriz Rosales Vicente bekarosales87@gmail.com \\ https://orcid.org/0000-0002-6473-9037 \\ Universidad de La Habana (Cuba)
}




\section{Resumen}

El artículo describe las prácticas culturales asociadas a la celebración de los quince años en Cuba, un rito de paso cuyas características socio-históricas develan las complejidades y reestructuraciones de la realidad social en que se inscriben, incluyendo el consumo cultural. El artículo usa como método principal el registro y visualización de esas prácticas culturales, desde la postura del micro-relato subjetivo de la antropología audiovisual. Todo ello permitió la producción de un documental que examina los códigos simbólicos y patrones estéticos de las prácticas culturales y comunicativas asociadas a la celebración de los quince años, al tiempo que aporta una dimensión experiencial al análisis.

Palabras clave: Prácticas culturales; documental; rito de paso.

\section{Abstract}

The article describes the cultural practices associated with the celebration of quince years old in Cuba, a rite of passage whose socio-historical characteristics reveal the complexities and restructuring of the social reality in which they are registered, including cultural consumption. The article uses, as principal method, the recording and display of these cultural practices, from the position of micro-story subjective of the audiovisual anthropology. All this allowed the production of a documentary that examines the symbolic codes and aesthetic patterns of the cultural and communicative practices associated with the celebration, while providing an experiential dimension to the analysis.

Keywords: Cultural practices; documentary, rite of passage.

En Cuba, la celebración de los quince años se ha abordado desde las Ciencias Políticas, la Sociología y la Psicología, pero nunca antes por la Comunicación. Sin embargo, la categoría de investigación de prácticas culturales sí ha sido objeto de diversas investigaciones desde la perspectiva comunicológica cubana, como son Avatares habaneros en las postrimerías del XIX. Acercamiento a las prácticas culturales/ simbólicas en el espacio urbano de La Habana durante la Tregua Fecunda 1878-1895 (Galletti Hernández, 2011) y ¿Descubriendo lo Real Maravilloso? Acercamiento a las prácticas culturales gestionadas por el proyecto sociocultural Callejón de Hamel y su contribución identitaria (Otaño, 2014), entre otros. 
Asimismo, la bibliografía consultada ofrece un panorama que no describe el componente comunicativo de estas prácticas culturales, teniendo en cuenta las investigaciones más actualizadas sobre comunicación y cultura. Por ello, la presente investigación ofrece elementos novedosos y actualizados sobre el fenómeno, que se ha estudiado a través de la etnografía como método de investigación, las prácticas culturales como categoría científica de acento multicultural, y el documental antropológico como registro audiovisual.

A los efectos de la presente investigación, las prácticas culturales asociadas a los quince años como celebración incluyen un grupo de actividades tales como tiempo de ahorro del capital monetario e inversión del mismo; consensos familiares donde se elabora el cronograma de la celebración; el tipo de festejo, que puede ir desde la fiesta tradicional, viajes familiares a un hotel o cualquier sitio de interés del adolescente, así como una cena con la familia y amigos allegados; la divulgación de la celebración con amigos, vecinos, compañeros de escuela, entre otros; visitas a estudios fotográficos y casas organizadoras de eventos donde se alquilan trajes y sus accesorios, y visitas a salones de belleza. Esta gama de acciones son actos de comunicación regidos por códigos simbólicos que persiguen como objetivo transmitir valores, la necesidad de legitimación en la sociedad por parte de las familias, su estatus socio-económico, entre otros.

A partir de la etnografía, la investigación recurre a la construcción de relatos que evidencien este escenario y muestren la realidad de la familia cubana ante las exigencias correspondientes -0 no- a un estatus social. El documental antropológico ofrece las posibilidades narrativas y reflexivas para mostrar el fenómeno a partir de cada microhistoria, su contexto y los actores sociales que intervienen (Ruiz y Aguirre, 2015). Por ello, el objetivo general de la investigación es producir un documental antropológico sobre las prácticas culturales en las celebraciones de los quince años en Cuba a través de las historias en torno a esta celebración de cuatro familias habaneras.

\section{Referentes de las celebraciones de los quince años en Cuba}

Diversas son las referencias acerca de cuál es el origen de la celebración de los quince años en Cuba. Algunos autores consideran que es resultante de una sincretización de las costumbres europeas de presentación de las señoritas en sociedad con los ritos de iniciación indígenas. Las fiestas de quince años son una celebración que indica un status quo determinado del individuo y transmite valores, preferencias, así como relaciones intrafamiliares y sociales, al igual en la mayoría de los países latinoamericanos (Cavagnoud, 2012).

Question, Vol. 1, N. ${ }^{\circ}$ 62, abril-junio 2019. ISSN 1669-6581

Instituto de Investigaciones en Comunicación | Facultad de Periodismo y Comunicación Social | Universidad Nacional de La Plata La 
Las primeras referencias a estas celebraciones surgen desde mediados del siglo XIX, como una moda entre las jóvenes de la época, que festejaban una gran fiesta conocida como primer salón, constituyendo el rito de iniciación de las féminas en la vida social y destacando el décimo quinto cumpleaños por encima del resto de sus aniversarios de vida, con un formato que respondía a códigos de prestigio y poder de la época, cuyas protagonistas eran siempre jóvenes de clase alta (Gutiérrez, 2007). Aunque las celebraciones de los quince años no eran privativas de la clase alta, sí marcaban una pauta; de ahí su connotación como exponentes del status quo y de la posición económica de la familia, ya fuere real o espuria.

En torno al fenómeno objeto de investigación, en Cuba han existido dos momentos de transición o ruptura social: el triunfo de la Revolución y el Período Especial. Con la Revolución se inicia un proceso de homogenización social y cultural en el que se defienden valores como la sencillez, la igualdad, la humildad. El Estado ocupa un rol preponderante en todas las esferas de la vida social y, por ende, marca qué dirección llevarán los ritos culturales. No desaparecieron ni las celebraciones de los quince años ni las bodas, pero se propiciaba que, a través de ellas, se expresaran los valores que defendía la ideología dominante. Paralelo a ello, se produjo un desapego a la Iglesia como institución, y todas las ritualidades de valor religioso pasaron a un segundo plano: el bautizo, la primera comunión y la boda por la iglesia, principalmente.

El llamado Período Especial, que ha sido considerado como la más grave crisis económica de la isla a partir de la caída del campo socialista europeo en la década de los noventa, también constituyó un retroceso en la vida social del país. La sociedad pierde la capacidad de mantener los procesos de homogenización y comienzan a desarrollarse tendencias de heterogeneización social. Los negocios relacionados con las celebraciones de los quince años ganaron auge, aunque todavía sin la magnitud de los existentes en la actualidad. En aquellos años existían casas de alquiler de trajes para las fiestas, y organizadores de fiestas que funcionaban al mismo tiempo como coreógrafo y decorador, así como fotógrafos. Surgen nuevas necesidades asociadas al consumo, por ende, una especie de industria cultural privada, legal o sumergida, como opción alternativa a casi todo lo que anteriormente estaba en manos del Estado: personas que se dedican a alquilar trajes, a organizar fiestas, a montar coreografías y a dar servicios de fotografía y video (Mendoza, Moras, Linares y Rivero, 2010).

Coincide este período con un cambio en las relaciones entre Cuba y los Estados Unidos; sobre todo con la comunidad cubana en La Florida. Las familias radicadas en Miami apoyan materialmente las celebraciones de sus parientes en la Isla enviando los trajes y las decoraciones de las fiestas, así mismo las remesas de dinero enviadas desde el exterior forman parte, según su monto y regularidad, del estatus socioeconómico de las familias 
cubanas. Al mismo tiempo, la Iglesia recupera su papel, y los ritos asociados a la religión católica empiezan a ganar espacios de preeminencia asociados a moral cristiana y las condiciones socioeconómicas inscritas en las tradiciones.

Según los resultados de una encuesta aplicada en las provincias cubanas de La Habana, Matanzas, Villa Clara y Santiago de Cuba, las investigadoras Briñas y Jiménez (2006), describen que las actividades que prefieren realizar las y los adolescentes al cumplir quince años son comprarse ropa y zapatos, hacerse fotos, organizar una fiesta o una comida familiar, ir a una casa en la playa y que les filmen un video. Las celebraciones objeto de estudio han seguido evolucionado hasta el momento de la presente investigación en estrecho vínculo con los cambios socio económicos del país y la estratificación social resultante de ellos.

\section{Diseño de investigación}

El diseño metodológico estuvo dirigido a examinar rutas teóricas que acercaran a los conceptos de cultura desde las prácticas culturales, las tradiciones, los ritos de paso y el consumo cultural; describir las prácticas culturales sobre las celebraciones de los quince años en Cuba en su evolución hasta hoy; analizar las prácticas comunicativas dentro de esas prácticas culturales; identificar las condicionantes socioeconómicas y culturales que están mediando en ellas y referir los elementos relacionados con la estética del documental antropológico, su metodología y técnicas principales- de interés para el audiovisual propuesto. En cuanto a la producción de un documental antropológico, fue necesario caracterizar las prácticas culturales, visibilizando las prácticas comunicativas en las celebraciones de los quince años en Cuba, a partir de cuatro familias habaneras de diferentes estratos socioeconómicos, y develar a través de los cuatro micro-relatos y desde la perspectiva del documental antropológico, las estructuras socioeconómicas y culturales visibles y sumergidas en estas prácticas, que distinguen a la sociedad cubana de hoy.

Los métodos y técnicas utilizados fueron la revisión bibliográfica documental de fuentes documentales y empíricas (expertos y estudiosos del fenómeno), que permitió analizar los presupuestos teóricos de las prácticas culturales, ritos de paso, papel de las familias, etcétera; la entrevista semi-estructurada a especialistas, acerca de sus percepciones e informaciones relativas al fenómeno; la entrevista no estructurada generada in situ como resultado de la observación y la indagación etnográfica, y que por tanto se aplicó a los sujetos protagonistas de las celebraciones de los quince años; y la observación participante y notas de campo para el 
registro de la vida diaria y acontecimientos importantes, realizada desde junio de 2016 hasta julio de 2017.

Acerca de la observación participante, resulta necesario declarar, que consistió en un proceso desde la posición de investigador-espectador, hasta la gradual conversión en investigadorparticipante del fenómeno estudiado (Angrosino, 2012). Se tuvo en cuenta además la influencia del propio proceso de investigación sobre el objeto de estudio, concibiendo la auto-etnografía como parte del proceso de construcción del conocimiento (Guerrero, 2014). Al principio, cada familia fue consciente de la presencia de la cámara y las intenciones investigativas previas al rodaje del documental, pero el grado de implicación alcanzado permitió una integración mayor con los sujetos y una perspectiva única desde la antropología audiovisual. Constituyó así una atención incrementada, estado de mayor alerta y observación de ángulo abierto, ampliada por el propósito añadido de estudiar los aspectos culturales tácitos de una situación social dada. Permitió la caracterización de las prácticas culturales y comunicativas, sus preparativos, y sus implicaciones sociales y emocionales.

"Resulta necesario estudiar los eventos sociales, psicológicos o educacionales en su ambiente natural (...) dicha necesidad la demuestra también la diferencia de resultados entre los estudios de laboratorio y los de campo" (Martínez, 2005: 3), por ello la investigación recurrió a una muestra de cuatro familias de adolescentes que estuvieran a punto de arribar a los quince años.

Para la pesquisa se tuvieron en cuenta las características del método etnográfico y su enfoque hacia el registro del conocimiento cultural. Por lo tanto, se concibió una muestra homogénea, para una mejor caracterización de las prácticas culturales por parte de ambos sexos: cinco adolescentes, de ellos cuatro son del sexo femenino (1) y uno del masculino. Todas las historias tienen como núcleo de conexión el estudio fotográfico al que acudieron. Allí fueron contactadas, elegido entonces un solo negocio (2) atendiendo a la viabilidad de la investigación y de la búsqueda de un nexo articulador para las historias y su expresión en la dramaturgia del documental. Sin embargo, la muestra fue intencional, sujeta a criterio del investigador, y adoptó una perspectiva de selección heterogénea dentro de su homogeneidad (3), dado que tuvo en cuenta el papel de la familia, su composición; el nivel de decisión real de los implicados, el estatus económico y social, y los lugares de residencia, de forma tal que se obtuviera una descripción lo más abarcadora posible de la celebración de los quince años como práctica cultural.

\section{Discusión de los resultados}

Question, Vol. 1, N. o 62, abril-junio 2019. ISSN 1669-6581

Instituto de Investigaciones en Comunicación | Facultad de Periodismo y Comunicación Social | Universidad Nacional de La Plata La 
En la actualidad, las celebraciones de quince constituyen una práctica híbrida, como resultado de los cambios económicos y socioculturales del país, al reincorporarse patrones estéticos procedentes de diferentes contextos y épocas. A ello han contribuido diversos factores como el desarrollo de las tecnologías digitales, el aumento en la rapidez y el alcance de las comunicaciones con el exterior, la apertura al turismo extranjero y, con ello, a estilos de vida más ligados al consumo e incremento de las relaciones con la familia emigrada al exterior.

Los contenidos culturales que refuerzan la dominación femenina son asociados mediante el rito a vivencias gratificantes para las adolescentes, por ello, a cada muchacha llega toda una representación secular elaborada a través de varias generaciones, no solo acerca de la manera de celebrar los quince años, sino también del valor y la importancia que va a tener ese momento en su vida.

La búsqueda de patrones para orientarse en medio de esa transición identitaria, crea un espacio propicio para que el guion moderno-ancestral de la celebración de los quince años sea asumido como una especie de guía cultural sobre cómo convertirse en mujeres. La quinceañera no es una mera pieza que se inserta pasivamente en un engranaje cultural articulado a sus espaldas: se trata de un personaje activo, que en este evento busca (y en gran medida encuentra), la satisfacción de necesidades muy propias de reconocimiento, nuevas impresiones, contacto interpersonal, autoafirmación, entre otras.

Actualmente, en las celebraciones de los quince años se han recuperado algunos elementos de los años 40 y 50, como el baile de un vals y el uso del vestuario distintivo de esos años, tanto en las ceremonias como en las fotografías. Más allá del estilo alegórico a los bailes de salón, en algunas coreografías se dramatizan contenidos tradicionalistas y patriarcales; sobre todo cuando a la quinceañera "la entregan", acto donde el padre o figura de autoridad "entrega" a la joven al novio, simbolizando una especie de traspaso de poder sobre la joven, que se produce entre la familia y el novio. Estas dramatizaciones refuerzan una concepción histórica de la adolescente como mujer objeto con la cual ellas parecen tener plena conformidad, aunque no plena conciencia.

La familia y su red social le otorgan una prioridad a la quinceañera como sujeto, pero a la vez refuerzan y legitiman mediante el rito una concepción patrimonial sobre ella, acentuada por su doble condición de mujer y adolescente. Como se celebra una transición vital que implica la aceptación de una nueva condición social, los contenidos definidores de dicha condición que se reconozcan en el discurso y en las dramatizaciones, marcarán en gran medida el tipo de aspiraciones que se generan con la adquisición del nuevo estatus. En términos de vivencia, es típico que en el momento de celebrar los quince, las muchachas se sientan el centro de 
atención de su familia y sus amigos y encuentren un espacio de satisfacción de múltiples necesidades.

La madre es la figura central de la celebración y la más aludida por las quinceañeras en la preparación del ritual. Como tendencia, todas las figuras femeninas, como tías y abuelas tienen un lugar relevante frente a sus homólogos masculinos. El padre asume en gran medida el mayor peso de los gastos, reproduciendo una vez más el papel de proveedor, no desprovisto de afectividad.

En cuanto al tiempo de preparación para las celebraciones, este puede estar en un lapso de varios meses o un año para las fiestas más sencillas, que no incluyen vals ni alquiler de salones. Las celebraciones más suntuosas llevan varios años de preparación. Los costos, según la apreciación de estas muchachas y sus padres, oscilan entre los 1000 y los 3500 CUC (4).

El tiempo de preparación también incluye la preparación de la joven o el joven adolescente, que en muchos casos se someten a dietas para controlar el peso, procedimientos estéticos que van desde el tinte del cabello hasta depilación definitiva y blanqueamiento de manchas de la piel, y ejercicios que acentúen un estado físico ideal.

En la celebración de los quince años en Cuba se siguen patrones elitistas y cánones de moda. Un ejemplo es la recurrencia de una gran fiesta, basada en estereotipos impuestos por la industria cultural, provenientes de culturas extranjeras, con patrones repetitivos como el gran cake, las coreografías de vals, tango o música pop, entre otras, manifestaciones asociadas al lujo y la ostentación.

Los nuevos dispositivos (teléfonos móviles, entre los más relevantes) que funcionan como soportes digitales para ver, intercambiar, consumir, música, películas, seriales, videojuegos, etcétera, funcionan como movilizadores de estado de opinión, de interacciones, comportamientos, estilos y en dependencia de contextos y circunstancias, como indicadores de estatus, distinciones y desigualdades a nivel social a partir del tipo de acceso que se tenga a estos dispositivos y el tipo de acceso -lo que se esté dispuesto a pagar- a contenidos culturales a través de estos dispositivos.

En cuanto a la red de negocios dedicados a eventos de esta índole, su número y proporciones se han incrementado a causa de fenómenos sociales y culturales que, al promover una participación más numerosa y variada de actores (ya sean institucionales o por cuenta propia), alienta la creación de pequeños negocios como estudios fotográficos o salones para fiestas. Estos sitios acogen a profesionales que, según sus ingresos, tienen que tributar al Estado mediante un impuesto, determinado por la Oficina Nacional de Administración Tributaria (ONAT), como es el caso de los fotógrafos, estilistas, organizadores de eventos, diseñadores, 
editores, catering, entre otros afines a este tema. Este sector privado, o cuentapropista, ha desplazado por completo al sector estatal, al que sólo se recurre para el alquiler de determinados salones de fiesta, pero mediante la coordinación y decoración del local a cargo de los cuentapropistas.

Hoy, las casas de alquiler de trajes siguen existiendo como negocio independiente, pero los organizadores de fiestas o estudios fotográficos ya poseen su propio vestuario abundante y diverso, accesorios y adornos; cada negocio tiene su coreógrafo, decoradores e incluso su corte de baile por si la quinceañera opta por ello. Son más solicitados los servicios de negocios que sean capaces de dar respuesta integral a todas las demandas asociadas a la celebración de los quince años, lo cual determina la paulatina disminución de negocios dedicados a una sola variante o arista de las celebraciones. En todo el país existen grandes estudios fotográficos privados, con equipamiento de última generación y trabajadores con un alto nivel de especialización, por lo cual el producto final es cada vez más completo, sobre todo en la capital del país.

\section{Prácticas comunicativas asociadas}

Se realice o no una fiesta, y sin importar el costo de la celebración, todos los adolescentes hembras y varones-, se fotografían para configurar un álbum de fotos, que contiene en su mayoría fotos elaboradas mediante montajes digitales y fotos de estudio, y que se realizan en negocios privados fundamentalmente. Dentro de la diversidad de opciones y estilos disponibles, se pudo identificar tres categorías fundamentales (según la nomenclatura empleada por las propias quinceañeras y quinceañeros): las de estilo, artísticas y naturales.

Las fotos de estilo son aquellas en las que las muchachas aparecen vistiendo trajes largos de diferentes colores, que pueden estar adornados con encajes, sombreros, guantes, tiaras, sombrillas y abanicos; generalmente muy maquilladas y con peinados elaborados, en escenarios que intentan recrear un ambiente colonial (salones con lámparas, espejos y jarrones, escaleras, rejas, fuentes y jardines).Para los varones, las fotos de estilo consisten en posturas sobrias, vestidos con traje y corbata, sin remontarse a ningún ambiente colonial u otra época pasada.

En las fotos artísticas, la quinceañera posa con expresión angelical, recostada en cojines, sosteniendo algún instrumento musical que transmita la idea de delicadeza, generalmente un violín o guitarra. Por lo general, en estas instantáneas aparecen maquilladas discretamente para dar la sensación de naturalidad. La segunda variante de la fotografía artística muestra a 
las jóvenes casi siempre semidesnudas, o con ropa provocativa, y con un maquillaje llamativo. Se imitan, por ejemplo, posturas provenientes de los bailes de striptease, en escenarios que simbolizan el nuevo componente sexual de la adolescente que arriba a sus quince años, aunque muchas veces no se es consciente de ello. En estos casos, la imagen de la quinceañera aparece como parte de la portada de una revista de modas, un calendario, un anuncio publicitario, llaveros, posters, gigantografías, según los gustos de la joven y del presupuesto económico disponible. Para los varones, las fotos artísticas suelen ser una reproducción de poses, vestuario y accesorios similares a los cantantes masculinos de modas, sobre todo de cantantes de reggaetón, género urbano de gran acogida en ese grupo etario. Aunque lo importante es lucir masculinos, en posiciones dominantes que expresen fuerza y seguridad, cada vez más las fotografías tomadas a los quinceañeros se acercan a las poses adoptadas por las muchachas, revelando las nuevas concepciones con respecto a la belleza y al cuidado del cuerpo masculino.

Las fotos naturales, por su parte, son aquellas en que la muchacha aparece con su propia ropa (casi siempre la ropa nueva que se ha comprado para la ocasión), con una apariencia más cercana a su imagen real. En este tipo de fotos participan tanto muchachas como varones, y pueden tener lugar en el estudio, o ser tomadas en exteriores, preferiblemente en locaciones donde se aprecie la naturaleza. Son comunes aquí las fotos en playas, parques naturales o instalaciones turísticas.

Los álbumes de fotos normalmente abarcan fotos de cada una de las categorías descritas, constituyendo un acto simbólico cuyo valor fundamental no es la realización del acto en sí, sino su representación en imágenes que quedarán para la posteridad, en el cual las y los adolescentes encarnan las múltiples maneras de ser mujer/hombre que reciben como herencia e imposición sociocultural al cumplir quince años.

Otras opciones relacionadas con la fotografía son el photobook en 3D. La revista (simula las publicaciones dedicadas al mundo de la moda y los espectáculos, con pequeños escritos que describen novedades y secretos de la quinceañera/o, del mismo modo que se dedicarían en revistas tales como Vanidades, Life o Cosmopolitan) (5); ampliaciones o gigantografías desde $20 \times 30 \mathrm{~cm}$ hasta $100 \times 80 \mathrm{~cm} \circ 200 \times 80 \mathrm{~cm}$. También se hacen postales con fotografías no incluidas en el photobook o la revista, llaveros de metal o acrílico, jarras, pulóveres e imanes para poner sobre superficies metálicas. El costo total de estas prácticas comunicativas va desde los 220 CUC hasta cifras superiores a los 600 CUC.

En cuanto al video, existen varios momentos de filmación o registro audiovisual: el video de la sesión fotográfica (muestra el cambio de imagen de la adolescente mientras la maquillan para la sesión de fotos, los cambios de vestuario, la presencia de la familia, la salida a sitios 
reconocidos para fotografiarse en ellos. Este material es acompañado por temas musicales, por lo general baladas del agrado de la quinceañera, con el propósito de animar el montaje del audiovisual); y el video de la fiesta (bastante similar al anterior, se inicia con la joven maquillándose y preparándose para la ceremonia, se filma saliendo de su casa y llegando al salón de la celebración, capta los principales momentos dentro de la fiesta, las distintas coreografías a bailar con la corte de parejas y el brindis con los invitados, todo ello con entrevistas cortas a los familiares e invitados acerca de la homenajeada, como transiciones de un momento a otro).

Recientemente, el registro audiovisual de estas celebraciones ha incorporado el making off como nueva tendencia. Se enfoca en lo que ocurre en el set de fotografía del estudio y las locaciones externas, se hace mayor énfasis en la interacción del fotógrafo, la maquillista con la joven y su familia. El making off muestra también los preparativos de la ceremonia, filmando los ensayos de las coreografías, la decoración de las sillas, mesas, la pista de baile, así como la preparación de los familiares y la implicada principal desde la casa. Es un audiovisual dinámico con secuencias rápidas y musicalizadas completamente.

El video es una práctica surgida desde finales de los noventa, pero con mayores complejidades y recursos disponibles en la actualidad. Para los varones no se suelen realizar videos de estas características, ni se contratan profesionales para ello, aunque sí es muy elaborado en el caso de las muchachas.

\section{El documental antropológico Recuerdos de mis Quince}

Una vez identificadas las cuatro historias que servirían de hilo conductor para la caracterización de las prácticas culturales en las celebraciones de los quince años, se realizaron varias sesiones con cada una de las familias implicadas, facilitando el acercamiento del investigador con la historia en su propio espacio de desarrollo, y la familiarización de los sujetos con la cámara y el equipo de filmación. En esta etapa se estableció la colaboración con el canal Cubavisión Internacional y se definió el plan de rodaje.

La etapa de la producción resultó el momento de materializar las ideas concebidas en momentos anteriores de la creación del producto comunicativo. Durante este tiempo se realizó la filmación del documental, la cual se llevó a cabo en dieciocho llamados, algunos de ellos de ocho horas, en diez locaciones diferentes que contribuyeron al curso narrativo de las historias y a lograr un mejor trabajo fotográfico. 
Cada una de las cuatro familias con adolescentes próximos a sus quince años, constituyó un bloque temático dentro del documental. El primero, dedicado a las hermanas gemelas, mostró los deseos e intereses de las adolescentes con respecto a la celebración, el proceso de selección del vestuario y la selección del tipo de fotos que conformarían el álbum. El documental detalla la preparación a la que se someten estas adolescentes en aras de obtener la imagen deseada en las fotos, previa al día de la sesión de fotos, así como el proceso de toma de los fotogramas y el proceso de edición que se les hace a las fotografías que requerirán montajes digitales. Se muestra asimismo los lugares de paseo, ubicados en la zona turística de La Habana Vieja, municipio de La Habana, adonde la familia lleva a estas dos muchachas como parte de la celebración de sus quince años. En este primer bloque, es vital el testimonio de las adolescentes protagonistas describiendo sus expectativas, el uso que harán de sus fotos y demás soportes visuales, dada la tendencia creciente a compartir y difundir esas fotos a través de las redes sociales y círculos de amigos. También se entrevista a la madre y a la hermana mayor, quienes detallan el costo de estas prácticas, y sus motivaciones socioculturales para llevarlas a cabo. Estas entrevistas permiten igualmente una caracterización de los sujetos involucrados.

El segundo bloque se dedica a Diana, hija de una familia con mayor poder adquisitivo que puede, por tanto, hacer mayores demandas a sus padres con respecto a la celebración de sus quince, que incluyeron la estadía en un hotel turístico y la compra de un teléfono móvil de gama alta. En esta parte, además de la sesión fotográfica, se muestra la fiesta de los quince, y los ensayos coreográficos que ejecutan la propia quinceañera y sus amigos con vistas a su presentación en la noche de la fiesta. Este bloque, conformado también por testimonios de la quinceañera y sus familiares, enfatiza y demuestra la complejidad que puede alcanzar este tipo de celebración.

Seguidamente entra la historia de María Fernanda, proveniente de una familia de bajos recursos. Este hogar, conformado por una madre soltera con un salario inferior a los 30 CUC (6) mensuales, y la abuela, ama de casa, carece del apoyo económico o sentimental del padre, lo cual influye en el alcance y dimensión de la celebración. Además de las prácticas comunicativas asociadas (sesión fotográfica y adopción de una nueva imagen por parte de la quinceañera), este bloque muestra la cooperación de los familiares y compañeros de trabajo para pagar la celebración, que incluyó una fiesta en la casa de un familiar cercano. Allí se realizó la ceremonia de las velas descrita anteriormente, y también la grabación de un video no profesional.

La cuarta historia es la del joven Jorge Freddy, donde los sujetos implicados explican la tendencia por parte de los varones de asumir las prácticas comunicativas asociadas a estos 
festejos. Se detalla, por tanto, el desarrollo de la sesión fotográfica, el tipo de fotos y la imagen elegida por el joven para elaborar las gigantografías y otros soportes visuales. También se muestra el momento de la fiesta, realizada en un bar. Esta fiesta se distingue por la ausencia de protocolo o ceremonial, que sí están presentes en el caso de las fiestas para muchachas, y otra diferencia es el mayor consumo de alcohol que el que normalmente se permite a las muchachas. El tipo de ambientación y preparación del local reproduce igualmente los códigos de una sociedad patriarcal, que alienta determinados comportamientos diferenciados para hombres y mujeres.

Como conclusión de cada una de estas historias, se muestran entrevistas a los trabajadores del estudio fotográfico Wao!, quienes explican cuáles son las ofertas más demandadas por los quinceañeros y quinceañeras, su valoración de las prácticas y códigos audiovisuales que se manifiestan, y las diferencias y similitudes evidenciadas entre muchachas y muchachos. Por último, el documental registra a modo de resumen la entrega de los álbumes de fotos, exponiéndose el resultado final y constancia gráfica de la celebración, y una selección de entrevistas a cada uno de los adolescentes acerca de si perciben algún cambio con respecto a su estatus en la familia y redes de amigos, y qué expectativas o planes tienen a futuro.

Un recurso importante tenido en cuenta al planificar la estrategia de decodificación fue el uso de generadores con información en distintos momentos del documental. Se decidió utilizar este recurso para reforzar parte de la información develada a través de las entrevistas. También se utilizaron en la graficación, imágenes de fotos de quinceañeras de los setenta y ochenta, y las nuevas estéticas utilizadas en la actualidad, como apoyatura audiovisual al discurso, cuando los testimoniantes se referían a una u otra etapa, lo cual permite adquirir a través de la obra documental, una comprensión más completa del fenómeno.

Las imágenes contribuyeron a complementar las informaciones que ofrecen los entrevistados por medio de la visualidad que brindan las mismas, y, en general, cada uno de los elementos utilizados en el documental contribuye a que el espectador comprenda las diferentes aristas y particularidades de las celebraciones de los quince años en Cuba.

\section{Conclusiones}

De acuerdo con esta investigación, la celebración de los quince años en Cuba representa tanto para los adolescentes como para sus familias, un acto de relevancia sociocultural, que genera grandes expectativas y supone un festejo en el que deben visibilizarse rituales que dan cuenta de las inversiones económicas y el estatus social que representan. 
El consumo cultural del adolescente determina en gran medida la auto-percepción de su imagen personal, mientras que su auto-percepción de su presencia física determina buena parte de las prácticas comunicativas asociadas a la celebración -cantidad y tipo de fotos que integrarán el álbum, soporte de imágenes, etcétera-

La industria cultural resulta el punto de partida de estos patrones que a su vez conducen a una segmentación de públicos. En ese sentido, juegan un papel fundamental los nuevos consumos por parte de los adolescentes y sus familias, donde predominan los reality shows norteamericanos, y los programas y revistas dedicadas al star system hollywoodense. Las prácticas culturales en adolescentes están caracterizadas sobre todo por el consumo cultural de medios alternativos y audiovisuales. Están influenciados por la cultura empaquetada, así como por tendencias de moda foráneas.

Las prácticas culturales en torno a las celebraciones de los quince años en Cuba, más allá de la descripción de los patrones que se repiten y del fenómeno en sí, son fundamentalmente, actos de comunicación regidos por un código simbólico, y que no siempre tienen un correlato a nivel verbal consciente. En estos actos se están comunicando estatus, valores, preferencias estéticas y patrones de gusto.

El consumo cultural, los patrones de belleza, la reproducción de estereotipos sexistas y patriarcales, dan cuenta de dos aspectos fundamentales que están transversalizando la sociedad cubana actual: retrocesos en elementos de emancipación y concepciones ideoestéticas y, por otro lado, marcada estratificación económica de la sociedad cubana que determina los consumos culturales. Sin embargo, contrario a lo que esta estratificación supone en términos de expectativa, esos elementos no se ajustan, por lo que aumenta la complejidad del fenómeno.

Tanto el uso del método etnográfico como la determinación del documental antropológico permitieron aproximarse a las características más representativas del género documental y reflexionar en torno a las complejas rutinas de trabajo que supone un producto comunicativo de esta índole. Permitió además acercarse a la temática a partir de la experiencia de personas involucradas en el proceso de la celebración de los quince años, lo que enriqueció la puesta documental al aportar la dimensión experiencial a la subjetividad y emotividad del tema de análisis. 
(1) En una de las familias se trataba de dos hermanas gemelas, por lo tanto, el número de familias en la muestra es inferior al número de adolescentes que celebraban sus quince años.

(2) El escenario de convergencia de las cuatro historias fue el estudio de fotografía Wao, ubicado en el municipio habanero de Mariano. El estudio fotográfico posee un salón de 37 metros cuadrados, climatizado, con una colección de vestidos de quinceañeras y todo tipo de accesorios y calzado. En el trabajan dos fotógrafos profesionales y un camarógrafo, varias estilistas encargadas del maquillaje y peinado de las quinceañeras, y una fashionista, cuyo trabajo es cuidar la imagen de la joven en el set, su maquillaje y sus gestos a la hora de posar de acuerdo a las últimas tendencias de la moda o gusto personal del cliente. Poseen equipamiento profesional moderno: seis lámparas, tres cámaras con diversos lentes, rebotadores de luz, y un auto para traslados a locaciones exteriores.

(3) Se considera homogénea dado que se seleccionaron historias donde los adolescentes optaban por una fiesta, junto con las prácticas comunicativas asociadas a ella, como núcleo fundamental de su celebración, y no por otras opciones, por ejemplo, estadías en hoteles turísticos.

(4) Nomenclatura que designa a la Moneda Libremente Convertible, vigente en Cuba, cuyo valor equivale a veinticinco pesos cubanos. De ello se entiende que mil CUC equivalen a veinticinco mil pesos cubanos.

(5) Los precios de las revistas oscilan entre 1.50 CUC y 5.00 CUC por pliego (cada pliego son cuatro caras), en dependencia del tipo de papel, dimensiones, número de ejemplares, tinta empleada y método de impresión. El diseño de la portada y los escritos que conforman la revista tienen un costo añadido al servicio de impresión.

(6) Equivale a setecientos cincuenta pesos cubanos.

\section{Bibliografía}

Angrosino, M. (2012). Etnografía y observación participante en la investigación cualitativa. Madrid, España: Morata.

Briñas, Y. y Jiménez, A. (2006). Valoración de los adolescentes en torno a las celebraciones de quince. Informe de Investigación, Centro de Estudios sobre la Juventud.

Cavagnoud, R. (2012). La celebración de los quince años como rito de salida de la infancia para las chicas en el Perú. Umbrales, 22, pp. 95-106. Recuperado de https://halshs.archives-ouvertes.fr/file/index/docid/1002985/ filename/a08.pdf

Galleti Hernández, D. (2011). Avatares habaneros en las postrimerías del XIX. Acercamiento a las prácticas culturales/ simbólicas en el espacio urbano de La Habana durante la Tregua Fecunda (Tesis de pregrado). Universidad de La Habana, Cuba.

Guerrero Muñoz, J. (2014). El valor de la auto-etnografía como fuente para la investigación social: del método a la narrativa. Revista Internacional de Trabajo Social y Bienestar, 3, pp. 237-242. Recuperado https://bit.ly/2IHyHZs

Gutiérrez, L. M. (2007). Celebrar los quince años: sentido social de un rito. Informe de investigación, Instituto Cubano de Investigación Cultural Juan Marinello.

Question, Vol. 1, N. o 62, abril-junio 2019. ISSN 1669-6581

Instituto de Investigaciones en Comunicación | Facultad de Periodismo y Comunicación Social | Universidad Nacional de La Plata La 
Martínez Miguélez, M. (2005). El método etnográfico de investigación. Recuperado de http://prof.usb.ve/miguelm/metodoetnografico.html

Mendoza, Y.; Moras, P. E.; Linares, C.; y Rivero, Y. (2010). El consumo cultural y sus prácticas en Cuba. Informe de investigación, Instituto Cubano de Investigación Cultural Juan Marinello.

Otaño, C. (2014). ¿Descubriendo lo Real Maravilloso? Acercamiento a las prácticas culturales gestionadas por el proyecto sociocultural Callejón de Hamel y su contribución identitaria. (Tesis de pregrado). Universidad de La Habana, Cuba.

Ruiz Méndez, M. y Aguirre Aguilar, G. (2015). Etnografía audiovisual, un acercamiento al método y a sus aplicaciones. Revista de Estudios sobre las Culturas Contemporáneas, XXI(41), pp. 67-96. 